\title{
Metallic Seed Nanolayers for Enhanced Nucleation of Nanocrystalline Diamond Thin Films
}

\author{
Josephus G. Buijnsters ${ }^{1, *}$, Jean-Pierre Celis ${ }^{1}$, Ruud W.A. Hendrikx ${ }^{2}$, Luis Vázquez ${ }^{3}$ \\ 1 Department of Metallurgy and Materials Engineering, KU Leuven, Kasteelpark \\ Arenberg 44, B-3001 Leuven, Belgium \\ ${ }^{2}$ Department of Materials Science and Engineering, Delft University of Technology, \\ Faculty of 3mE, Mekelweg 2, 2628 CD Delft, The Netherlands \\ ${ }^{3}$ Instituto de Ciencia de Materiales de Madrid, Consejo Superior de Investigaciones \\ Científicas, Sor Juana Inés de la Cruz 3, Cantoblanco, E-28049 Madrid, Spain \\ * Corresponding author. E-mail: Ivan.Buijnsters@mtm.kuleuven.be. Phone: +32 (0)16 32 \\ 12 60. Fax: +32 (0)16321991.
}




\section{ABSTRACT:}

The enhancement of the nucleation and subsequent growth of nanocrystalline diamond (NCD) films with a submicron thickness control on silicon substrates is demonstrated by using a sputter deposition of six different metallic ( $\mathrm{Cr}, \mathrm{Mo}, \mathrm{Nb}, \mathrm{Ti}, \mathrm{V}$, and $\mathrm{W}$ ) seed nanolayers. The effectiveness of altered surface morphology and surface chemistry is discussed. We show that the number density of nanodiamond particles embedded on the nanorough metallic surfaces after an ultrasonic seeding step together with the dynamic surface chemistry during hot-filament chemical vapor deposition of diamond determine the nucleation kinetics, microstructure and surface topography of the NCD films. Overall, the smoothest NCD layer (root-mean-square roughness $10 \mathrm{~nm}$ ) was obtained with the highest seed density of diamond nanoparticles anchored to the metallic (W) surface. In particular, the rapid carbide-forming metals $\mathrm{Mo}, \mathrm{Nb}$ and $\mathrm{W}$ showed the highest number density of diamond crystallites formed during the NCD nucleation stage, which resulted in dense, uniform and very smooth NCD films. Much rougher NCD films (17-37 nm) were obtained on the $\mathrm{Cr}, \mathrm{Ti}$, and $\mathrm{V}$ nanolayers that did not form carbides rapidly. Importantly, the carbon phase purity of the grown NCD films remains unaffected by the presence of different metallic seed nanolayers. Furthermore, we have assessed that the metallic nanolayer surface morphology does not play a relevant role in the enhancement of the seeding step.

KEYWORDS: nanocrystalline diamond films, nucleation, seeding, metallic surfaces, chemical vapor deposition, diamond nanoparticles. 


\section{INTRODUCTION}

Diamond combines a number of superior mechanical, optical, thermal, and electrical properties, which has triggered the development of diamond films in a wide range of scientific and technological applications. ${ }^{1}$ The vast progress made in chemical vapor deposition (CVD) techniques during the last two decades has further stimulated the use of synthetic diamond films as protective coatings, heat spreaders, optical windows and biological platforms, ${ }^{1-3}$ and their use in electrochemistry, ${ }^{4}$ microelectromechanical devices, ${ }^{5}$ and biosensors, ${ }^{6}$ and so forth. Diamond thin films are usually grown by either plasma-assisted CVD or hot-filament CVD (HF-CVD) techniques, based on the activation of gaseous mixtures containing methane as carbon precursor. Research activities on nanograined, polycrystalline diamond have increased rapidly, and new synthesis methods of nanocrystalline $e^{2,7,8}$ and ultrananocrystalline ${ }^{9}$ diamond films have been developed. Nanocrystalline diamond (NCD) grows in hydrogen-rich CVD environments, and so-called ultra-nanocrystalline diamond (UNCD) is generally synthesized in argon-rich, hydrogen-poor gas mixtures. ${ }^{2}$ UNCD is synthesized with a high renucleation rate during CVD processing and it consists of very small crystalline diamond grains (about 2-5 $\mathrm{nm}$ in size) with a relatively high fraction of $s p^{2}$-bonded carbon connecting the grains. On the other hand, NCD is typically grown at initially high nucleation site densities. The diamond grain size in NCD films can differ from the diameter of the nucleating nanosized diamond particles up to about $150-200 \mathrm{~nm}$ at the growing film surface. Thus, NCD films span a continuum in grain sizes, morphologies, and material properties depending on the substrate properties, film thickness and applied growth conditions. 
The critical step in the CVD of diamond thin films on non-diamond (foreign) substrates is the diamond nucleation step. It generally requires an artificial creation of diamond nucleation sites on the substrate surface, since the high surface energy of diamond limits the formation of stable diamond nuclei from the gas phase without any substrate pretreatment. Different nucleation procedures have been established based on either ex situ or in situ methods with highly varying results. The popular in situ approach based on the bias enhanced nucleation ${ }^{10,11}$ prior or during the initial stages of diamond film growth gives a high density of diamond nucleation, but is limited to electrically conductive substrates and results in inhomogeneous nucleation if applied in HF-CVD. ${ }^{12}$ Therefore, ex situ methods are most widely applied for nucleation enhancement purposes. Manual scratching or abrading of the substrate surface with diamond grit $^{13,14}$ enhances the nucleation density of diamond by many orders of magnitude compared with nonscratched substrates (up to $10^{9} \mathrm{~cm}^{-2}$ in the case of silicon ${ }^{15}$ but this procedure leads to the introduction of surface defects and it is limited to mechanically robust substrate materials such as hard metal, refractory metals and steels. ${ }^{16-18}$ Commonly, ultrasonic agitation in a diamond slurry or dispersions of nanodiamond (ND) particles is applied. ${ }^{15,19,20}$ In particular, when ultrasonic agitation is performed in a solution of monodisperse, or socalled ultradispersed, nanodiamond particles of 5-10 $\mathrm{nm}$ in size, ${ }^{21-23}$ extremely high diamond nucleation densities (in the range $10^{11}-10^{12} \mathrm{~cm}^{-2}$ ) can be obtained. The ND particles adhere to the substrate surface by van der Waals interactions and/or electrostatic forces and so act as nucleation seeds in the subsequent diamond CVD growth process. Ideally, a compact monolayer of diamond nanoparticles uniformly dispersed on the 
substrate surface enables the synthesis of extremely smooth, dense and thin diamond films.

Recent research ${ }^{24}$ has shown that electrostatic grafting (or self-assembly) on surface modified substrates can result in very high ND particle densities by taking advantage of the electrostatic interactions between the ND particles and the substrate surface. Alternatively, by a heat treatment in air, the ND particle surface becomes mainly covered by carboxylic groups and a negative surface charge is obtained when suspended in water. An electrostatic self-assembly seeding process with such modified ND particles on copper and $\mathrm{SiO}_{2}$ substrates was reported. ${ }^{25,26}$ Also, the deposition of two-dimensional monolayers of ND particles by combined ultracentrifugation and electrophoresis techniques has been shown lately. ${ }^{27}$ Yet, no studies have been reported that focused on the (possible) relationship between the topography of the substrate surface and the assembly of ND particle seeds onto it.

In numerous studies devoted to the growth of diamond thin films on ferrous and cemented carbide substrates, metallic interlayers were effectively employed to suppress the large uptake of carbon, to suppress the out-diffusion of highly reactive $\mathrm{Fe}$ and $\mathrm{Co}$ atoms, and to improve the adhesion of the diamond films on the substrate. ${ }^{28-32}$ In addition, it has long been known that under conventional pretreatment conditions, such as manual scratching, the diamond nucleation densities on carbide-forming substrates ( $\mathrm{Si}$, Mo, W) are typically one or two orders of magnitude higher than those on substrates that do not form carbides $(\mathrm{Cu}, \mathrm{Au}){ }^{33}$ In this view, a number of recent studies focused on a pre-coating of silicon with thin $(\leq 50 \mathrm{~nm})$ metallic seed layers such as $\mathrm{W},{ }^{34,35} \mathrm{Cr},{ }^{36}$ and $\mathrm{Mo}^{37,38}$ followed by ultrasonic agitation with ND powders. These studies demonstrated a 
more uniform and denser nucleation of diamond during CVD. This offers the opportunity to produce very thin NCD and UNCD films reducing the surface roughness and eliminating interfacial voids. Yet, there is little understanding of the effects of the altered surface chemistry and surface morphology, associated with the coating of the silicon substrate by these metals, on the seeding by ND particles and the early stages of diamond film formation. In particular, the surface coating morphology could play a significant role since the surface nano-asperities could promote the seed adhesion and then enhance the seeding density. So, there is a strong need for a direct comparison of the effectiveness of different metal seed nanolayers for the synthesis of nanostructured diamond thin films.

Therefore, in this work, we studied the enhancement of the nucleation and growth of NCD thin films by using six different metallic ( $\mathrm{Cr}, \mathrm{Mo}, \mathrm{Nb}, \mathrm{Ti}, \mathrm{V}$, and $\mathrm{W})$ seed nanolayers. We aimed at the rapid formation of smooth and dense NCD films at a relatively low substrate temperature of about $650{ }^{\circ} \mathrm{C}$ to deal with the hurdles of the prevailing high deposition temperature and of the low nucleation and growth rates common to the diamond CVD process, ${ }^{1}$ especially to the conventional hot-filament assisted CVD process without argon stock gas. ${ }^{39}$ In particular, we investigated the role of the nanotopography of the metallic layers on the efficiency of seeding by nanodiamond particles as well as the effect of a rapid carburization of the metallic surfaces during the early stages of diamond film formation on the microstructure and smoothness of the NCD films. Atomic force microscopy, micro-Raman spectroscopy, scanning electron microscopy, and grazing incidence x-ray analyses were employed for sample characterization. 


\section{EXPERIMENTAL METHODS}

2.1. Materials Deposition and Substrate Pretreatment. Chromium (Cr), molybdenum (Mo), niobium $(\mathrm{Nb})$, titanium $(\mathrm{Ti})$, vanadium $(\mathrm{V})$, and tungsten $(\mathrm{W})$ seed nanolayers of about $90 \mathrm{~nm}$ thickness were deposited onto six different mirror-polished silicon (100) wafers (Ø $300 \mathrm{~mm}$ ) by RF sputtering using high purity (99.9999\%) argon as the working gas. Sputtering was done in a Veeco Nexus 800 sputter deposition tool at the Philips Innovation Services, MiPlaza (The Netherlands), using metallic targets of $99.95 \%$ to 99.999\% purity and single wafer deposition chambers to avoid cross-contamination. The RF sputtering power was $1000 \mathrm{~W}$ and the argon gas flow was adjusted to minimize film stress (max. $100 \mathrm{MPa}$ tensile or compressive stress). Samples of $1 \times 1 \mathrm{~cm}^{2}$ size were laser cut from each of the six different metal-coated silicon wafers. As a seeding treatment prior to diamond deposition, these samples were ultrasonically treated in a suspension of ND powders of detonation origin (Sigma-Aldrich, particle size $<10 \mathrm{~nm}$ ) in isopropanol for $1 \mathrm{hr}$, followed by a rinsing in pure isopropanol for $1 \mathrm{~min}$. Following, diamond was deposited on the seeded samples in a home-built HF-CVD reactor using a methane-tohydrogen gas mixture of $2.5 \%$. The following deposition parameters were maintained throughout the entire study: substrate temperature of about $650{ }^{\circ} \mathrm{C}$, filament temperature of $2,200{ }^{\circ} \mathrm{C}$, system pressure of 15 mbar, filament-to-substrate distance of $(10 \pm 2) \mathrm{mm}$, and total gas flow of 304.5 SCCM (standard cubic centimeters per minute). The methane and hydrogen gas flows were fixed at 7.5 SCCM and 297 SCCM, respectively. A precarburized tantalum filament coil of $0.5 \mathrm{~mm}$ diameter was used throughout. The filament and substrate temperatures were monitored with an optical pyrometer (model M90-V, Mikron Infrared Inc.) and a K-type thermocouple placed at the back side of the 
substrates, respectively. The substrate temperature $\left(650 \pm 15^{\circ} \mathrm{C}\right)$ was maintained using a PID controller (model 2416, Eurotherm Ltd.) with an induction heating system (model TR1, Cheltenham Induction Heating Ltd.) for heating up the Mo-substrate holder combined with an active water cooling of the same.

2.2 Characterization. Scanning electron microscopy (SEM; JEOL JSM $6330 \mathrm{~F}$ and NOVA NANOSEM 230 equipment (C) FEI) operating with a VCD (low-voltage and high-contrast for backscattered electrons) detector) and atomic force microscopy (AFM; Nanoscope IIIa from Veeco and Agilent 5500 from Agilent) operated in tapping mode with silicon cantilevers (nominal radius of $10 \mathrm{~nm}$ ) were used to characterize the surface topography of the samples before and after diamond nucleation and NCD film growth. AFM topographic images of $512 \times 512$ points were taken at different sample spots and different areas (from $1 \times 1 \mu^{2}$ up to $20 \times 20 \mu \mathrm{m}^{2}$ ) were imaged. The corresponding roughness data were averaged from a minimum of three measurements. Microstructural analyses of the diamond deposits were performed by micro-Raman spectroscopy using an Ar-ion laser $\left(514.5 \mathrm{~nm}\right.$ ) at $800-2000 \mathrm{~cm}^{-1}$ (Renishaw System 1000) using a $50 \times$ objective with a spot size of about $2 \mu \mathrm{m}$. Grazing incidence X-ray diffraction (XRD) was performed to study the (crystalline) phases formed at the substrate surface during diamond deposition. $\mathrm{CuK}_{\alpha}$ radiation $(40 \mathrm{kV}, 40 \mathrm{~mA})$ was used for both types of measurements. XRD patterns were recorded at a constant grazing angle of $6^{\circ}$ and $2 \theta$ angles between $6^{\circ}$ and $130^{\circ}$ with a step size of $0.02^{\circ}$ and a step time of $10 \mathrm{~s}$.

\section{RESULTS AND DISCUSSION}

\subsection{Substrate Seeding by ND Particles}


The first step in this study consisted in a morphological characterization by AFM of the metallic seed nanolayers before and after the ultrasonic seeding pretreatment with the ND powder. In this way, any correlation between the surface morphology (i.e., surface roughness correlations) of the as-sputtered metallic nanofilms and the embedding of the ND powder seeds could be established.

\subsubsection{Morphological Characterization of As-sputtered Metallic Nanolayers}

The uncoated Si wafer substrates are extremely smooth with root-mean-square (RMS), or $\mathrm{R}_{\mathrm{q}}$, roughness of $0.1-0.2 \mathrm{~nm} .^{38}$ Therefore, the topography of the coated samples is mainly determined by the sputtered metallic thin films. The layer thickness and RMS surface roughness of the six metallic films are given in Table 1. Both value sets are within relatively narrow windows and the $\mathrm{Nb}$ layer has lowest roughness $(0.5 \mathrm{~nm})$, whereas highest values $(1.5-1.6 \mathrm{~nm})$ are obtained on the $\mathrm{V}$ and $\mathrm{W}$ film surfaces. 
Table 1. Layer Thickness and Root-Mean-Square (RMS) Surface Roughness of the As-Sputtered Metallic Nanolayers, and Number Density of NanoDiamond (ND) Particle Seeds on These Films.

\begin{tabular}{cccc}
\hline & Layer & RMS surface & ND seed \\
Metal & thickness & roughness & density \\
& $(\mathrm{nm})$ & $(\mathrm{nm})$ & $\left(\times 10^{10} \mathrm{~cm}^{-2}\right)$ \\
& & & \\
\hline $\mathrm{Cr}$ & $92 \pm 1$ & $1.2 \pm 0.1$ & $0.3 \pm 0.1$ \\
$\mathrm{Mo}$ & $94 \pm 2$ & $0.9 \pm 0.1$ & $1.1 \pm 0.2$ \\
$\mathrm{Nb}$ & $91 \pm 2$ & $0.5 \pm 0.1$ & $1.3 \pm 0.2$ \\
$\mathrm{Ti}$ & $89 \pm 1$ & $1.2 \pm 0.1$ & $1.2 \pm 0.2$ \\
$\mathrm{~V}$ & $92 \pm 2$ & $1.6 \pm 0.2$ & $1.5 \pm 0.3$ \\
$\mathrm{~W}$ & $92 \pm 2$ & $1.5 \pm 0.2$ & $3.5 \pm 0.5$ \\
\hline \hline
\end{tabular}

Figure 1 shows the AFM topographic images of the different as-sputtered metallic surfaces. It is evident that the morphology of the respective crystalline surfaces is quite different, since the average sizes and shapes of the surface grains vary significantly. For example, the sputtered $\mathrm{Cr}$ surface is highly porous due to the formation of agglomerates of elongated grains (Figure 1a). Also the $\mathrm{Nb}$ film surface (Figure 1c) consists of textured agglomerates of elongated grains, but of significantly smaller size and with denser structure. On the other hand, the surface grains of the Mo (Figure 1b), Ti (Figure 1d), and V (Figure 1e) nanolayers are round shaped and more uniform in size. Finally, the surface of the W film exhibits relatively flat areas contrasted by cavities ranging in lateral size up 
to about $275 \mathrm{~nm}$. Note that the individual spots of lighter contrast that can be observed on nearly all the metallic surfaces and that vary in size from about 10 to $100 \mathrm{~nm}$ are likely liquid droplets of the sputter target material that have been incorporated in the metallic films.

(FIGURE 1)

\subsubsection{Morphological Characterization of Seeded Metallic Nanolayers}

The AFM topographic images obtained from the metallic nanofilms after the ultrasonic pretreatment with ND powders are presented in Figure 2. Obviously, there is a strong variation in size, distribution and average density of embedded ND particle seeds among the different metallic seed nanolayers. A relatively low number density of seeds of about $0.3 \times 10^{10} \mathrm{~cm}^{-2}$ (Table 1) is detected on the $\mathrm{Cr}$ film surface (Figure 2a). The seeds are mostly embedded as single ND particles as was concluded from a detailed inspection of the AFM images obtained at higher resolution (inset of Figure 2a). Note that the fact that the ND particles appear much larger in the AFM image than the effective core particle size $(\sim 10 \mathrm{~nm})$ is due to the convolution effect between AFM tip and ND particle. ${ }^{40}$ On all other metallic films (Figure 2b-f), both spatially separated and densely packed ND particle agglomerates are observed. Average seed densities range from $1.1 \times 10^{10} \mathrm{~cm}^{-2}$ to $3.5 \times 10^{10} \mathrm{~cm}^{-2}$ on the Mo and W surfaces, respectively (Table 1). Clearly, the highest number density and surface coverage by ND seeds is found on the W surface. The insets of Figure 2 show the presence of agglomerates consisting of a wide number range of ND particles. The formation of relatively large agglomerates (up to about $180 \mathrm{~nm}$ in lateral 
size) is most evident for the $\mathrm{Nb}$ and Ti surfaces (Figures $2 \mathrm{c}$ and $2 \mathrm{~d}$ ). Typical surface line profiles of the seeded metallic surfaces are shown in Figure $2 \mathrm{~g}$. The large variation in number density and height of the ND agglomerates among the different metallic surfaces is clear. Largest agglomerates (up to about $43 \mathrm{~nm}$ in height) are measured on the $\mathrm{Nb}$ surface, whereas few and mostly single ND particles are detected on the Cr surface.

(FIGURE 2)

For the metallic nanolayers under investigation in this study, the ND seed particle densities are comparable or somewhat higher than that on the pristine Si surface $(\sim 1 \times$ $\left.10^{10} \mathrm{~cm}^{-2}\right),{ }^{38}$ except in the case of $\mathrm{Cr}$. The self-assembly seeding of the ND colloids could be explained on the basis of interfacial forces. In principle, the variation in nanoscale roughness of the different metallic film surfaces could cause a dissimilar assembly of ND seeds. Therefore, the effect of surface topography of the sputtered nanofilms on the embedding of ND particles was studied into more detail (see Supporting Information). In particular, we analyzed the eventual relationship between the lateral roughness correlations, which are related to the surface nano-asperities, and the seeding efficiency. From our quantitative AFM analysis of the morphology of the different metallic nanofilms and the calculated number densities of embedded ND seeds (Table 1) it can be concluded that there is no direct correlation between the topography of the substrate surface and the accumulation of ND seeds. Electrostatic interactions between substrate surface and the ND particles seem thus to dominate the embedding (adhesion and aggregation) of the ND seeds. ${ }^{26}$ 


\subsection{Early Stage of NCD Film Formation}

\subsubsection{Morphological Characterization of NCD Nucleation}

Advanced nucleation and the formation of almost fully closed NCD thin films can already be observed on several of the seeded metallic surfaces after only 2 min of HFCVD processing. SEM images taken from the surfaces of the different metallic nanolayers are displayed in Figure 3. Diamond crystals in the range from about $9 \mathrm{~nm}$ (single diamond crystallites) to $75 \mathrm{~nm}$ (mostly heavily twinned and coalesced diamond grains) are observed on all the metallic surfaces. The fastest nucleation of NCD material takes place on the seeded Mo, Nb, and $\mathrm{W}$ surfaces. The surface coverage by diamond deposits on the $\mathrm{Nb}$ and $\mathrm{W}$ surfaces even exceeds $90 \%$. On the other hand, the surface coverage on the seeded $\mathrm{Cr}$ film is only about $40 \%$ and the porous structure of the sputtered Cr surface can still be observed. Additional experiments with 2 min of diamond deposition on non-seeded metallic surfaces (not shown) demonstrated very sluggish diamond nucleation kinetics (estimated maximum diamond nucleation densities are only about $10^{6} \mathrm{~cm}^{-2}$ ), which confirms that the use of the metallic surfaces alone is not enough for efficient diamond nucleation and that seeding with ND particles is essential for diamond nucleation enhancement and NCD film formation.

(FIGURE 3)

\subsubsection{Surface Chemistry during NCD Nucleation and Film Formation}

Micro-Raman spectroscopy was employed to evaluate the carbon bonding of the deposits formed after the nucleation stage. Raman spectra recorded on the different metallic 
surfaces after 2 min of HF-CVD growth are shown in Figure 4. The Raman spectra are characterized by five clear signals labeled from 1 to 5 with increasing Raman shift. The diamond peak (2) is centered at $1333 \mathrm{~cm}^{-1}$ and the Raman signals corresponding to the so-called D-band (3) and G-band (5) of graphite ${ }^{41}$ are observed at $1365 \mathrm{~cm}^{-1}$ and 1590 $\mathrm{cm}^{-1}$, respectively. At $1136 \mathrm{~cm}^{-1}$ (1) and about $1480 \mathrm{~cm}^{-1}$ (4), signals related to transpolyacetylene (t-PA) can be distinguished. ${ }^{41}$ The carbon-related Raman signals from the diamond deposits on the six different metallic surfaces are quite similar, except in the case of the V surface. Noticeably, the relative intensities of the signals associated with tPA (1 and 4) in this particular case are much lower than those recorded on the other metallic surfaces. Also, the signals related to graphite (3 and 5) are relatively strong in the case of diamond nucleation on the V seed layer. The highest diamond peak intensities are observed on the Mo, $\mathrm{Nb}$ and $\mathrm{W}$ surfaces, which can be explained by the relatively high surface coverage by diamond crystallites of these surfaces (Figure 3).

\section{(FIGURE 4)}

Changes in the crystalline structure and solid phase composition of all the six metallic surfaces upon exposure to the reactive HF-CVD process were analyzed by grazing incidence XRD. Experimental data corresponding to the $\mathrm{Cr}, \mathrm{V}$, and $\mathrm{W}$ nanolayers only are presented here to discuss the three different cases of highly diverse diamond nucleation rates and surface chemistry involved. The corresponding grazing incidence XRD patterns before and after 2 min of diamond nucleation are shown in Figure 5. The six different as-sputtered metallic films are all crystalline and phase pure layers, except 
the $\mathrm{V}$ thin film (Figure 5b), which is partly amorphous (see the little amorphous bump at about $18^{\circ}$ in the lower scan). After 2 min of diamond nucleation, three different types of chemical conversions can be distinguished among the six different metallic interfaces. In the case of $\mathrm{Cr}$ (Figure 5a) and $\mathrm{Ti}$, the metallic films are completely transformed into metal silicides. The rapid intermixing of the metallic and silicon elements from the thin film and the substrate at the elevated CVD growth temperature leads to the formation of $\mathrm{CrSi}_{2}$ and a mixture of $\mathrm{TiSi}_{2}$ and $\mathrm{Ti}_{5} \mathrm{Si}_{3}$, respectively. Secondly, an oxidation of the metallic surface is detected in the case of $\mathrm{V}$ (Figure $5 \mathrm{~b}$ ), where the formation of the $\mathrm{VO}_{1.27}$ phase is observed. Thirdly, the most common chemical conversion is the (partial) carburization of the metallic surfaces, as is the case for the Mo, Nb, and $\mathrm{W}$ nanolayers. Regarding the $\mathrm{W}$ thin film (Figure $5 \mathrm{c}$ ), the little intense reflections at $2 \theta=34.5^{\circ}, 2 \theta=$ $56.0^{\circ}$ and $2 \theta=61.4^{\circ}$ can be assigned to $\mathrm{W}_{6} \mathrm{C}_{2.54}$. On the other hand, the Mo thin film is completely transformed into $\mathrm{Mo}_{2} \mathrm{C}$ and the $\mathrm{Nb}$ nanofilm is converted into a mixture of $\mathrm{Nb}$ and $\mathrm{NbC}_{0.79}$.

\section{(FIGURE 5)}

No reflections from the nucleated diamond crystallites can be found in the corresponding XRD patterns, likely because diamond has a relatively low scattering cross section for $\mathrm{XRD}$ analysis due to its low atomic mass. The two broad bands at $2 \theta=57.2^{\circ}$ and $2 \theta=$ $86.6^{\circ}$ that can be distinguished in nearly all the XRD patterns are probably the result of thermal diffuse scattering caused by thermally excited lattice vibrations of the silicon substrate, ${ }^{42}$ since the measurements were performed at room temperature. More 
importantly, on all the exposed metallic surfaces with the exception of Mo, a very broad peak ('halo') at about $2 \theta=18^{\circ}$ is recorded, which results from incoherent scatter and indicates the presence of amorphous solid material. The (partial) amorphization of the metallic surfaces is most probably accelerated by a rapid carbon uptake at the elevated substrate temperature of about $650^{\circ} \mathrm{C}$.

\subsection{Growth of Smooth and Dense NCD Films}

Prolonged HF-CVD of diamond (total growth time $20 \mathrm{~min}$ ) results in the development of closed, well-adhered and crack-free NCD thin films on all the seeded metallic nanolayers. NCD films with a thickness in the range 300-350 nm were thus produced, which implies an average growth rate of the NCD films of about $1 \mu \mathrm{m} \mathrm{h}^{-1}$. Cross-section SEM images of the NCD films grown on top of the Cr, $\mathrm{V}$ and $\mathrm{W}$ nanofilms are shown in Figure 6 . The NCD film deposited on the Cr seed nanolayer (Figure 6a) displays a large inhomogeneity. Semispherical, nanofaceted diamond growth clusters of several hundreds of $\mathrm{nm}$ in lateral size have coalesced into a relatively rough and bumpy NCD film. Interfacial voids and open areas are observed in-between these clusters, which is probably the result of the non-uniform and relatively sluggish nucleation on the seeded $\mathrm{Cr}$ surface (Figure 3). Also, notice the thickness increase of the $\mathrm{Cr}$ seed nanolayer by about $100 \%$ with respect to that of the as-sputtered Cr film. Conversely, the NCD films that were formed on the five other seeded metallic nanolayers are much more uniform, smooth and compact, and reveal a columnar rather than an equiaxed microstructure. In all these cases, little to no increase in thickness of the metallic nanofilms is detected. As examples, the cross-section views of the NCD films grown on the $\mathrm{V}$ and $\mathrm{W}$ seed nanolayers are displayed in Figures $6 \mathrm{~b}$ and 
6c, respectively. In contrast, diamond growth on uncoated silicon, although analogously seeded with ND particles and at similar HF-CVD conditions, does not result in the formation of closed NCD films after 20 min, but leads to coalesced NCD nucleation clusters only. ${ }^{38}$ This clearly evidences the accelerated nucleation and growth of NCD thin films by using the metallic seed nanolayers.

(FIGURE 6)

AFM topographic images of the NCD films grown on the six different seeded metallic nanofilms are displayed in Figure 7. The surface morphology of the NCD films varies strongly among the different samples. In the case of NCD film growth on the seeded $\mathrm{Cr}$ and $\mathrm{Ti}$ nanolayers (Figures $7 \mathrm{a}$ and $7 \mathrm{~d}$, respectively), the surface morphology is characterized by surface features with major height variations over relatively large lateral dimensions. The NCD film grown on the seeded V interlayer (Figure 7e) exhibits a typical cauliflower-like morphology ${ }^{43,44}$ that is frequently observed in CVD processes. ${ }^{43-}$

${ }^{45}$ In fact, all the synthesized NCD films in this study are of a lower crystalline order than the strongly faceted NCD films with high purity grown from extremely high diamond seed densities and carbon-lean gas atmosphere, ${ }^{2}$ and they are commonly referred to as 'ballas' or cauliflower-type diamond. ${ }^{2,39}$ The smoothest NCD films with most uniform surface morphology were grown on the $\mathrm{Mo}, \mathrm{Nb}$, and $\mathrm{W}$ metallic thin films (Figures $7 \mathrm{~b}$, 7c, and 7f, respectively). In these three cases, the cauliflower-like structures are limited to lateral dimensions of several hundreds of nanometers only. 
(FIGURE 7)

Figure 8 shows the RMS roughness of the NCD films as well as the surface coverage after 2 min of diamond nucleation as a function of the initial ND seed density for the six different metallic thin films. Clearly, the smoothest $(10 \mathrm{~nm})$ and roughest $(37 \mathrm{~nm}) \mathrm{NCD}$ films are formed with the highest and lowest seed densities of ND particles on the W and Cr nanolayers, respectively. This also reflects on the comparatively high ( $\sim 90 \%)$ and low $(\sim 40 \%)$ surface coverages by diamond crystallites after 2 min of nucleation on these two metallic thin films. On the other hand, there is a strong variation in surface coverage after diamond nucleation and in RMS roughness of the NCD films synthesized on the Mo, Nb, Ti, and V metallic surfaces. No direct relation between these two surface characteristics and the ND seed density can be deduced on those metallic surfaces. Nevertheless, it is evident that overall the surface coverage after diamond nucleation and the RMS roughness of the NCD films are inversely related to each other. In other words, the higher is the surface coverage, the lower is the RMS roughness of the grown NCD films. Interestingly, the smoothest NCD films (RMS roughness 10-12 nm) are formed on the rapid carbide-forming metals $\mathrm{Mo}, \mathrm{Nb}$ and $\mathrm{W}$. Much rougher NCD films (RMS roughness 17-37 $\mathrm{nm}$ ) are obtained on the $\mathrm{Cr}$, $\mathrm{Ti}$, and $\mathrm{V}$ interlayers that do not form carbides rapidly.

\section{(FIGURE 8)}

The bonding structure of the NCD films grown on the six different seeded metallic surfaces is very similar (Figure 9). The signals from the non-diamond carbon phases (1, 
3-5) dominate the Raman spectra, as was the case after diamond nucleation (Figure 4). Only, the relative intensities of the Raman signals related to t-PA (1 and 4) have increased slightly as compared to those in the Raman spectra recorded after diamond nucleation. The relatively high methane-to-hydrogen gas ratio of $2.5 \%$ used for the NCD film growth results in a high supersaturation of carbon precursors at the cost of gaseous etchants such as atomic hydrogen. ${ }^{43,46}$ Such a growth scenario promotes a relatively high number of defects that facilitate crystal twinning and the re-nucleation of diamond crystallites during the NCD film growth. ${ }^{47}$ The grain boundary structure thus produced is commonly characterized by the incorporation of minority non-diamond carbon phases, such as amorphous carbon and t-PA. ${ }^{47}$ However, visible Raman spectra of NCD materials are dominated by emission from the grain boundaries, although these regions typically account for less than $5 \%$ of the grown material. ${ }^{48}$

(FIGURE 9)

\section{DISCUSSION}

\subsection{Interactions Between Substrate Surface and ND Particles}

For the first time, we have shown that there is no direct correlation between the topography of the substrate surface and the accumulation of ND seeds via ultrasonic seeding by performing a quantitative analysis of the morphology of the different metallic nanofilms by AFM and of the embedding of ND seeds on these surfaces. However, in general, the nanoscale surface roughness of the substrate does strongly affect the adhesion force between the substrate surface and an embedded particle. It was previously 
reported that the adhesion force on nanorough surfaces is primarily determined by the distribution of asperity heights ${ }^{49}$ and the contact interaction of the asperity and the adhering particle is found to dominate the interaction. ${ }^{50}$ It has been speculated that the introduction of surface nano-asperities by substrate coating could thus promote the seed adhesion and thus enhance the seeding density of ND particles on silicon substrates. ${ }^{35,38}$ This effect is rather small for most of the sputter-coated metallic surfaces under investigation in this study, since relatively comparable values of the number density of ND particle seeds on the various metallic surfaces and the pristine silicon surface have been derived (in the order of about $1 \times 10^{10} \mathrm{~cm}^{-2}$ ). In fact, electrostatic interactions between the substrate surface and the ND particles, rather than van der Waals interactions, appear to dominate the embedding (adhesion and aggregation) of the ND seeds. This is in line with several recent reports that focused on the seeding of ND particles by electrostatic self-assembly. ${ }^{24-26,51,52}$ Electrostatic grafting on substrates (with or without surface modification) can result in a very high density and uniformity of ND particles if a properly selected surface modification and fractionalization of the ND particles are employed to improve their dispersion and to separate those particles into a more narrow range of particle sizes. ${ }^{26,52}$

Ideally, ND particles are anchored to the substrate surface as seeds of single grain size for NCD film growth, but it is well known that the formation of ND particle agglomerates is difficult to avoid. The formation of nanoparticle agglomerates on the metallic film surfaces in this study could be due to the direct embedding of such agglomerates being present in the alcoholic suspension itself and/or a re-agglomeration of well dispersed ND particles on the sample surfaces upon evaporation of the liquid 
solution at the end of the ultrasonic pretreatment. Usually, ND particles produced by the detonation process are tightly bound in aggregates that are difficult to separate into monodisperse particle colloids. ${ }^{25,53}$ No dynamic light scattering data were available for the ND suspension in isopropyl alcohol used in the present study, but it likely contains a broad range of particle sizes. In fact, a nearly full sedimentation of the suspension was observed after about 2 hours after completion of the ultrasonic agitation. On the other hand, it is commonly recognized that the so-called zeta potential ${ }^{26,52}$ of the ND particles in suspension on the one hand and that of the substrate surface on the other hand determine the colloidal behavior and self-assembly of ND particles on the substrate surface. Opposite values (negative vs. positive, or vice versa) of the respective zeta potentials could be obtained by tailoring the substrate and ND particle surfaces with different functional groups. Recent studies have shown that a heat treatment of the pristine detonation ND powder in air $^{54,55}$ or in hydrogen gas ${ }^{56}$ can yield monodisperse colloids, which will likely favor the spreading and embedding of single ND grains on the different metal(oxide) surfaces.

\subsection{Surface Carburization}

It is well known that carbon diffusion is crucial for diamond nucleation and film growth and the metallic interfaces play an important role in the diffusion process of carbon. In the case of the Mo seed nanolayer, a complete carburization into a single-phase $\mathrm{Mo}_{2} \mathrm{C}$ layer occurred within the first 2 min of diamond nucleation, which results from the high diffusion coefficient of atomic carbon in molybdenum and $\mathrm{Mo}_{2} \mathrm{C}^{57,58} \mathrm{Bahr}$ et al. ${ }^{59}$ showed that accumulation of carbon leads to the formation of $\mathrm{C}-\mathrm{C}$ bonds within the 
molybdenum carbide layer and that the growth of diamond on top of Mo only starts after the incubation time necessary to develop a carbide layer and to saturate the surface of the carbide with carbon. Likewise, Chen et $a l .{ }^{60,61}$ claimed that, as a consequence of the limited volume for carbon inward diffusion, the fast accumulation of carbon species in 300- and 400-nm thick W and Ti coatings, respectively, on a Si substrate, results in the enhanced formation of $\mathrm{W}-\mathrm{C}$ and Ti-C phases at the Si-metal interface, which in turn leads to a faster diamond nucleation. Unfortunately, there are very few reports on the highresolution transmission electron microscopy analysis of diamond nucleation on metallic surfaces. Chen et al. ${ }^{62,63}$ recently demonstrated that the nucleation of UNCD and NCD on Mo coatings proceeds on top of $\mathrm{Mo}_{2} \mathrm{C}, \mathrm{MoC}$, and possibly graphite. Alternatively, Haenen and co-workers ${ }^{64,65}$ provided clear evidence that carbon diffuses through $\mathrm{TiO}_{2}$ sol-gel seed layers and that dispersed ND seeds that were intentionally buried underneath partially convert to amorphous carbon during diamond film growth. This carbon diffusion and conversion from diamond to amorphous carbon made the seed areas below the $\mathrm{TiO}_{2}$ layer grow and bend the $\mathrm{TiO}_{2}$ layer upwards to create the nucleation center of the diamond film. ${ }^{65}$ These recent findings strongly support the crucial role of carbon diffusion in the diamond nucleation and film formation stages. In conclusion, it is expected that the carburization and the fast accumulation of carbon atoms within the subsurface region of all the seed nanolayers of the Group 4-6 transition metals under investigation in this study, in combination with the number density of initially embedded ND particle seeds, determine the nucleation rate of diamond.

\subsection{NCD Film Growth}


Figure 8 shows that the smoothest and roughest NCD films are formed with the highest and lowest seed densities of ND particles on the W and Cr nanolayers, respectively. Also, there is a clear correlation between the surface coverage (or number density of developed nuclei) after diamond nucleation and the RMS roughness of the grown NCD films. The higher number density of nucleated diamond crystallites on the rapid carbide-forming metals $\mathrm{Mo}, \mathrm{Nb}$, and $\mathrm{W}$ leads to a faster coalescence of diamond nuclei and a more rapid formation of closed NCD films as compared to the $\mathrm{Cr}$, Ti and V surfaces that do not noticeably form metal carbides at the NCD-metal interface. The enhanced diamond nucleation kinetics results in a denser film microstructure with minor fluctuations in surface height, i.e. in significantly smoother NCD films. This promotes vertical growth with a columnar-like microstructure (Figures $6 \mathrm{~b}$ and $6 \mathrm{c}$ ) vs. three-dimensional growth around fewer diamond nuclei ${ }^{34}$ as is the case for $\mathrm{Cr}$, for example (Figure 6a). This is fully in line with the outcomes of several previous studies ${ }^{43,66,67}$ that showed that the absolute value of the RMS roughness of nanograined diamond films depends both on the gas mixture and the primary nucleation site density.

In conclusion, the carbon phase purity of the grown NCD films is determined by the precursor gas composition and is thus not affected by the presence of different metallic seed nanolayers, although the kinetics of diamond nucleation and NCD film growth as well as the surface roughness of the NCD thin films vary significantly among the different metals studied in this work.

\section{CONCLUSIONS}


The nucleation enhancement of submicron thick NCD films during HF-CVD was demonstrated for the surface modification of silicon substrates by a sputter deposition of metallic nanolayers followed by ultrasonic seeding using ND particles. Comparison of the enhancement of the nucleation and growth of NCD films by using six different metallic ( $\mathrm{Cr}, \mathrm{Mo}, \mathrm{Nb}, \mathrm{Ti}, \mathrm{V}$, and $\mathrm{W})$ seed nanolayers shows that the number density of ND particles embedded on the nanorough metallic surfaces by ultrasonic seeding prior to HF-CVD together with the dynamic surface chemistry during HF-CVD of diamond determine the nucleation kinetics, microstructure and surface topography of the NCD films thus produced. The carbon phase purity of the NCD films is determined by the precursor gas composition applied during HF-CVD and is thus not affected by the presence of different metallic seed nanolayers. No direct correlation between the surface topography of the metallic nanofilms and the accumulation of ND seeds could be established for the ultrasonic seeding pretreatment. Electrostatic interactions between substrate surface and the ND particles seem to dominate the embedding (adhesion and aggregation) of the ND seeds.

Our study shows that the smoothest NCD films (RMS roughness of only $10 \mathrm{~nm}$ ) are obtained with the highest number density of ND seed particles anchored to the metallic surface, which is the case for the $\mathrm{W}$ nanolayer. In fact, very smooth and dense NCD films are only developed on the metallic nanolayers that lead to a rapid formation of metal carbides and a very high number density of created diamond nuclei in the early stages of HF-CVD (i.e., on the Mo, $\mathrm{Nb}$, and $\mathrm{W}$ surfaces). In the case of using seeded $\mathrm{Cr}$ and Ti nanolayers, the metallic films are rapidly converted into their metal silicides and relatively rough NCD films with cauliflower-like surface morphology are obtained. NCD 
film growth on the seeded $\mathrm{V}$ nanolayer suffers from a rapid oxidation of the metallic surface and a comparatively rough NCD film is produced.

\author{
AUTHOR INFORMATION \\ Corresponding Author \\ *E-mail: Ivan.Buijnsters@mtm.kuleuven.be. Telephone: +32 (0) 163212 60. Fax: +32 \\ (0) 16321990 .
}

\title{
ACKNOWLEDGEMENT
}

We thank A. Valera for help with the cross-section SEM measurements. JGB would like to thank the Executive Research Agency of the European Union for funding under the Marie Curie grant "NANODIA" (272448). This work has been partially supported by Comunidad Autónoma de Madrid (project No. S2009/PPQ-1642, AVANSENS) and Ministerio de Economía y Competitividad (FIS2012-38866-C05-05).

\section{Supporting Information Available:}

Study of the influence of the surface roughness correlations of the metallic seed nanolayers on the seeding with nanodiamond particles. This information is available free of charge via the Internet at http://pubs.acs.org. 


\section{REFERENCES}

(1) May, P. W. The New Diamond Age? Science 2008, 319, 1490-1491.

(2) Butler, J. E.; Sumant, A. V. The CVD of Nanodiamond Materials. Chem. Vap. Deposition 2008, 14, 145-160.

(3) Huang, H.; Chen, M.; Bruno, P.; Lam, R.; Robinson, E.; Gruen, D.; Ho, D. Ultrananocrystalline Diamond Thin Films Functionalized with Therapeutically Active Collagen Networks. J. Phys. Chem. B 2009, 113, 2966-2971.

(4) Kraft, A. Doped Diamond: A Compact Review on a New, Versatile Electrode Material. Int. J. Electrochem. Sci. 2007, 2, 355-385.

(5) Auciello, O.; Birrell, J.; Carlisle, J. A.; Gerbi, J. E.; Xiao, X.; Peng, B.; Espinosa, H. D. Materials Science and Fabrication Processes for a New MEMS Technology Based on Ultrananocrystalline Diamond Thin Films. J. Phys.: Condens. Matter 2004, 16, R539-R552.

(6) Raina, S.; Kang, W. P.; Davidson, J. L. Fabrication of Nitrogen-Incorporated Nanodiamond Ultra-Microelectrode Array for Dopamine Detection. Diamond Relat. Mater. 2010, 19, 256-259.

(7) Zeng, L.; Peng, H.; Wang, W.; Chen, Y.; Lei, D.; Qi, W.; Liang, J.; Zhao, J. Kong, X.; Zhang, H. Nanocrystalline Diamond Films Deposited by the Hot Cathode Direct Current Plasma Chemical Vapor Deposition Method with Different Compositions of $\mathrm{CH}_{4} / \mathrm{Ar} / \mathrm{H}_{2}$ Gas Mixture. J. Phys. Chem. C 2008, 112, 1401-1406. 
(8) Tsugawa, K.; Ishihara, M.; Kim, J.; Koga, Y.; Hasegawa, M. Nucleation Enhancement of Nanocrystalline Diamond Growth at Low Substrate Temperatures by Adamantane Seeding. J. Phys. Chem. C 2010, 114, 3822-3824.

(9) Gruen, D. M. Electron Transport and the Potential of Ultrananocrystalline Diamond as a Thermoelectric Material (Chapter 5). In Ultrananocrystalline Diamond: Synthesis, Properties and Applications; Shenderova, O. A.; Gruen, D. M. (Eds.): William Andrew: Norwich, NY, USA, 2006; pp 157-184.

(10) Stoner, B. R.; Ma, G.-H. M. ; Wolter, S. D.; Glass, J. T. Characterization of BiasEnhanced Nucleation of Diamond on Silicon by Invacuo Surface-Analysis and Transmission Electron-Microscopy. Phys. Rev. B 1992, 45, 11067-11084.

(11) Arnault, J. -C.; Saada, S.; Delclos, S.; Rocha, L.; Intiso, L.; Polini, R.; Hoffman, A.; Michaelson, S.; Bergonzo, P. Surface Science Contribution to the BEN Control on $\mathrm{Si}(100)$ and $3 \mathrm{C}-\mathrm{SiC}(100)$ : Towards Ultrathin Nanocrystalline Diamond Films. Chem. Vap. Deposition 2008, 14, 187-195.

(12) Chen, Q.; Yang, J.; Lin, Z. Synthesis of Oriented Textured Diamond Films on Silicon via Hot-Filament Chemical-Vapor-Deposition. Appl. Phys. Lett. 1995, 67, $1853-1855$.

(13) Arnault, J.; Demuynck, L.; Speisser, C.; Normand, F. Mechanisms of CVD Diamond Nucleation and Growth on Mechanically Scratched Si(100) Surfaces. Eur. Phys. J. B 1999, 11, 327-343.

(14) Ascarelli, P.; Fontana, S. Dissimilar Grit-Size Dependence of the Diamond Nucleation Density on Substrate Surface Pretreatments. Appl. Surf. Sci. 1993, 64, 307-311. 
(15) Buijnsters, J. G.; Vázquez, L.; ter Meulen, J. J. Substrate Pre-treatment by Ultrasonication with Diamond Powder Mixtures for Nucleation Enhancement in Diamond Film Growth. Diamond Relat. Mater. 2009, 18, 1239-1246.

(16) Buijnsters, J. G.; Shankar, P.; Gopalakrishnan, P.; van Enckevort, W. J. P.; Schermer, J. J.; Ramakrishnan, S. S.; ter Meulen, J. J. Diffusion-Modified Boride Interlayers for Chemical Vapour Deposition of Low-Residual-Stress Diamond Films on Steel Substrates. Thin Solid Films 2003, 426, 85-93.

(17) Buijnsters, J. G.; Shankar, P.; van Enckevort, W. J. P.; Schermer, J. J.; ter Meulen, J. J. The Adhesion of Hot-Filament CVD Diamond Films on AISI Type 316 Austenitic Stainless Steel. Diamond Relat. Mater. 2004, 13, 848-857.

(18) Buijnsters, J. G.; Shankar, P.; van Enckevort, W. J. P.; Schermer, J. J.; ter Meulen, J. J. Adhesion Analysis of Polycrystalline Diamond Films on Molybdenum by Means of Scratch, Indentation and Sand Abrasion Testing. Thin Solid Films 2005, 474, 186-196.

(19) Sumant, A. V.; Gilbert, P. U. P. A.; Grierson, D. S.; Konicek, A. R.; Abrecht, M.; Butler, J. E.; Feygelson, T.; Rotter, S. S.; Carpick, R. W. Surface Composition, Bonding, and Morphology in the Nucleation and Growth of Ultra-Thin, High Quality Nanocrystalline Diamond Films. Diamond Relat. Mater. 2007, 16, 718724.

(20) Varga, M.; Ižák, T.; Kromka, A.; Veselý, M.; Hruška, K.; Michalka, M. Study of Diamond Film Nucleation by Ultrasonic Seeding in Different Solutions. Centr. Eur. J. Phys. 2012, 10, 218-224. 
(21) Williams, O. A.; Douheret, O.; Daenen, M.; Haenen, K.; Osawa, E.; Takahashi, M. Enhanced Diamond Nucleation on Monodispersed Nanocrystalline Diamond. Chem. Phys. Lett. 2007, 445, 255-258.

(22) Williams, O. A.; Nesladek, M.; Daenen, M.; Michaelson, S.; Hoffman, A.; Osawa, E.; Haenen, K.; Jackman, R. B. Growth, Electronic Properties and Applications of Nanodiamond. Diamond Relat. Mater. 2008, 17, 1080-1088.

(23) Osawa, E. Monodisperse Single Nanodiamond Particulates. Pure Appl. Chem. 2008, $80,1365-1379$.

(24) Girard, H. A.; Perruchas, S.; Gesset, C.; Chaigneau, M.; Vieille, L.; Arnault, J. C.; Bergonzo, P.; Boilot, J.- P.; Gacoin, T. Electrostatic Grafting of Diamond Nanoparticles: A Versatile Route to Nanocrystalline Diamond Thin Films. ACS Appl. Mater. Interfaces 2009, 1, 2738-2746.

(25) Hees, J.; Kriele, A.; Williams, O. A. Electrostatic Self-assembly of Diamond Nanoparticles. Chem. Phys. Lett. 2011, 509, 12-15.

(26) Liu, X.; Yu, T.; Wei, W.; Yu, Z.; Xu, X. Enhanced Diamond Nucleation on Copper Substrates by Employing an Electrostatic Self-Assembly Seeding Process with Modified Nanodiamond Particles. Colloids Surf. A 2012, 412, 82-89.

(27) Schmidlin, L.; Pichot, V.; Josset, S.; Pawlak, R.; Glatzel, T.; Kawai, S.; Meyer, E.; Spitzer, D. Two-Dimensional Nanodiamond Monolayers Deposited by Combined Ultracentrifugation and Electrophoresis Techniques. Appl. Phys. Lett. 2012, 101, 253111. 
(28) Bareiss, C.; Perle, M.; Rosiwal, S. M.; Singer, R. F. Diamond Coating of Steel at High Temperatures in Hot Filament Chemical Vapour Deposition (HFCVD) Employing Chromium Interlayers. Diamond Relat. Mater. 2006, 15, 754-760.

(29) Fan, Q. H.; Fernandes, A.; Gracio, J. Diamond Coating on Steel with a Titanium Interlayer. Diamond Relat. Mater. 1998, 7, 603-606.

(30) Lopez, J.M.; Babaev, V. G.; Khvostov, V. V.; Albella, J. M. Highly Adherent Diamond Coatings Deposited onto WC-Co Cemented Carbides via Barrier Interlayers. J. Mater. Res. 1998, 13, 2841-2846.

(31) Buijnsters, J. G.; Shankar, P.; ter Meulen, J. J. Direct Deposition of Polycrystalline Diamond onto Steel Substrates. Surf. Coat. Technol. 2007, 201, 8955-8960.

(32) Xiao, X.; Sheldon, B. W.; Konca, E.; Lev, L. C.; Lukitsch, M. J. The Failure Mechanism of Chromium as the Interlayer to Enhance the Adhesion of Nanocrystalline Diamond Coatings on Cemented Carbide. Diamond Relat. Mater. 2009, 18, 1114-1117.

(33) Liu, H.; Dandy, D. S. Studies on Nucleation Process in Diamond CVD - An Overview of Recent Developments. Diamond Relat. Mater. 1995, 4, 1173-1188.

(34) Naguib, N. N.; Elam, J. W.; Birrell, J.; Wang, J.; Grierson, D. S.; Kabius, B.; Hiller, J. M.; Sumant, A. V.; Carpick, R. W.; Auciello, O.; et al. Enhanced Nucleation, Smoothness and Conformality of Ultrananocrystalline Diamond (UNCD) Ultrathin Films via Tungsten Interlayers. Chem. Phys. Lett. 2006, 430, $345-350$. 
(35) Chu, Y.- C.; Tu, C.- H.; Jiang, G.; Chang, C.; Liu, C.- P.; Ting, J.- M.; Lee, H.L.; Tzeng, Y.; Auciello, O. Systematic Studies of the Nucleation and Growth of Ultrananocrystalline Diamond Films on Silicon Substrates Coated with a Tungsten Layer. J. Appl. Phys. 2012, 111, 124328.

(36) Garratt, E.; AlFaify, A.; Yoshitake, T.; Katamune, Y.; Bowden, M.; Nandasiri, M.; Ghantasala, M.; Mancini, D. C.; Thevuthasan, S.; Kayani, A. Effect of Chromium Underlayer on the Properties of Nano-Crystalline Diamond Films. Appl. Phys. Lett. 2013, 102, 011913.

(37) Buijnsters, J. G.; Vázquez, L.; Galindo, R. E.; ter Meulen, J. J. Molybdenum Interlayers for Nucleation Enhancement in Diamond CVD Growth. J. NanoSci. NanoTechnol. 2010, 10, 2885-2891.

(38) Buijnsters, J. G.; Vázquez, L.; van Dreumel, G. W. G.; ter Meulen, J. J.; van Enckevort, W. J. P.; Celis, J. P. Enhancement of the Nucleation of Smooth and Dense Nanocrystalline Diamond Films by Using Molybdenum Seed Layers. $J$. Appl. Phys. 2010, 108, 103514.

(39) Lifshitz, Y.; Lee, C. H.; Wu, Y.; Zhang, W. J.; Bello, I.; Lee, S. T. Role of Nucleation in Nanodiamond Film Growth. Appl. Phys. Lett. 2006, 88, 243114.

(40) Fekete, L.; Kůsová, K.; Petrák, V.; Kratochvílová, I. AFM Topographies of Densely Packed Nanoparticles: A Quick Way to Determine the Lateral Size Distribution by Autocorrelation Function Analysis. J. Nanopart. Res. 2012, 14, 1062.

(41) Ferrari, A.C.; Robertson, J. Origin of the $1150-\mathrm{cm}^{-1}$ Raman Mode in Nanocrystalline Diamond. Phys. Rev. B 2001, 63, 121405. 
(42) Sztucki, M.; Metzger, T. H.; Kegel, I.; Tilke, A.; Rouvière, J. L.; Lübbert, D.; Arthur, J.; Patel, J. R. X-ray Analysis of Temperature Induced Defect Structures in Boron Implanted Silicon. J. Appl. Phys. 2002, 92, 3694-3703.

(43) Buijnsters, J. G.; Vázquez, L. Growth Dynamics of Nanocrystalline Diamond Thin Films Deposited by Hot Filament Chemical Vapor Deposition: Influence of Low Sticking and Renucleation Processes. J. Phys. Chem. C 2011, 115, 96819691.

(44) Castro, M.; Cuerno, R.; Nicoli, M.; Vázquez, L.; Buijnsters, J. G. Universality of Cauliflower-Like Fronts: From Nanoscale Thin Films to Macroscopic Plants. New J. Phys. 2012, 14, 103039.

(45) Buijnsters, J. G.; Camero, M.; Vázquez, L. Growth Dynamics of Ultrasmooth Hydrogenated Amorphous Carbon Films. Phys. Rev. B 2006, 74, 155417.

(46) May, P. W.; Mankelevich, Y. A. From Ultrananocrystalline Diamond to Single Crystal Diamond Growth in Hot Filament and Microwave Plasma-Enhanced CVD Reactors: A Unified Model for Growth Rates and Grain Sizes. J. Phys. Chem. C 2008, 112, 12432-12441.

(47) Klauser, F.; Steinmüller-Nethl, D.; Kaindl, R.; Bertel, E.; Memmel, N. Raman Studies of Nano- and Ultra-nanocrystalline Diamond Films Grown by HotFilament CVD. Chem. Vap. Deposition 2010, 16, 127-135.

Liu, X.; Klauser, F.; Memmel, N.; Bertel, E.; Pichler, T.; Knupfer, M.; Kromka, A.; Steinmüller-Nethl, D. Spectroscopic Studies of Nanocrystalline Diamond Materials. Diamond Relat. Mater. 2007, 16, 1463-1470. 
(49) Fuller, K. N. G.; Tabor, F. R. S. Effect of Surface-Roughness on Adhesion of Elastic Solids. Proc. R. Soc. London, A: Math. Phys. Sci. 1975, 345, 327-342.

(50) Rabinovich, Y. I.; Adler, J. J.; Ata, A.; Singh, R. K.; Moudgil, B. M. Adhesion Between Nanoscale Rough Surfaces - II. Measurement and Comparison with Theory. J. Colloid Interface Sci. 2000, 232, 17-24.

(51) Shenderova, O.; Hens, S.; McGuire, G. Seeding Slurries Based on Detonation Nanodiamond in DMSO. Diamond Relat. Mater. 2010, 19, 260-267.

(52) Lee, H.- J.; Jeon, H.; Lee, W.- S. Synergistic Interaction between Substrate and Seed Particles in Ultrathin Ultrananocrystalline Diamond Film Nucleation on $\mathrm{SiO}_{2}$ with Controlled Surface Termination. J. Phys. Chem. C 2012, 116, 91809188.

(53) Krüger, A. The Structure and Reactivity of Nanoscale Diamond. J. Mater. Chem. 2008, $18,1485-1492$.

(54) Osswald, S.; Yushin, G.; Mochalin, V.; Kucheyev, S. O.; Gogotsi, Y. Control of $\mathrm{sp}^{2} / \mathrm{sp}^{3}$ Carbon Ratio and Surface Chemistry of Nanodiamond Powders by Selective Oxidation in Air. J. Am. Chem. Soc. 2006, 128, 11635-11642.

(55) Pastrana-Martínez, L. M.; Morales-Torres, S.; Carabineiro, S. A. C.; Buijnsters, J. G.; Faria, J. L.; Figueiredo, J. L.; Silva, A. M. T. Nanodiamond-TiO 2 Composites $^{-}$ for Heterogeneous Photocatalysis. ChemPlusChem 2013, 78, 801-807.

(56) Williams, O. A.; Hees, J.; Dieker, C.; Jager, W.; Kirste, L.; Nebel, C. E. SizeDependent Reactivity of Diamond Nanoparticles. ACS Nano 2010, 4, 4824-4830. Rosa, C. J. Carbon Diffusion in $\mathrm{Mo}_{2} \mathrm{C}$ as Determined from Carburization of Mo. Metall. Trans. A 1983, 14, 199-202. 
(58) Mikhailov, S. N.; Ariosa, D.; Weber, J.; Baer, Y.; Hänni, W.; Tang, X.- M.; Alers, P. The Behavior of the Molybdenum-CVD Diamond Interface at HighTemperature. Diamond Relat. Mater. 1995, 4, 1137-1141.

(59) Bahr, D. F.; Bucci, D. V.; Schadler, L. S.; Last, J. A.; Heberlein, J.; Pfender, E.; Gerberich, W. W. Characterization of d.c.jet CVD Diamond Films on Molybdenum. Diamond Relat. Mater. 1996, 5, 1462-1472.

(60) Chen, L.- J.; Tai, N.- H.; Lee, C.- Y.; Lin, I.- N. Effects of Pretreatment Processes on Improving the Formation of Ultrananocrystalline Diamond. J. Appl. Phys. 2007, 101, 064308 .

(61) Chen, L.- J.; Liu, C.- C.; Tai, N.- H.; Lee, C.- Y.; Fang, W.; Lin, I.- N. Effects of Tungsten Metal Coatings on Enhancing the Characteristics of Ultrananocrystalline Diamond Films. J. Phys. Chem. C 2008, 112, 3759-3765.

(62) Chen, H.- C.; Liu, K.- F.; Tai, N.- H.; Pong, W.- F.; Lin, I.- N. On the Mechanism of Enhancing the Nucleation Behavior of UNCD Films by Mo-coating. Diamond Relat. Mater. 2010, 19, 134-137.

(63) Wei, Q.; Yang, T.; Zhou, K. C.; Ma, L.; Zheng, P.; Li, J.; Zhang, D.; Li, Z.; Yu, Z. M. Effect of Sputtered Mo Interlayers on Si (100) Substrates for the Deposition of Diamond Film by Hot Filament Chemical Vapor Deposition. Surf. Coat. Technol. 2013, 232, 456-463.

(64) Daenen, M.; Zhang, L.; Erni, R.; Williams, O. A.; Hardy, A.; Van Bael, M. K.; Wagner, P.; Haenen, K.; Nesládek, M.; Van Tendeloo, G. Diamond Nucleation by Carbon Transport from Buried Nanodiamond $\mathrm{TiO}_{2}$ Sol-Gel Composites. $A d v$. Mater. 2009, 21, 670-673. 
(65) Lu, Y.- G.; Verbeeck, J.; Turner, S.; Hardy, A.; Janssens, S. D.; De Dobbelaere, C.; Wagner, P.; van Bael, M. K.; Haenen, K.; Van Tendeloo, G. Analytical TEM Study of CVD Diamond Growth on TiO2 Sol-Gel Layers. Diamond Relat. Mater. 2012, 23, 93-99.

(66) Sternschulte, H.; Rabl, H. E.; Steinmüller-Nethl, D.; Tilg, B. Modelling the Influence of the Nucleation Density on Ultra Nano Crystalline Diamond Growth Morphology: Preliminary Results. Chem. Vap. Deposition 2008, 14, 232-235.

(67) Cicala, G.; Magaletti, V.; Senesi, G. S.; Tamborra, M. Smoothness Improvement of Micrometer- and Submicrometer-Thick Nanocrystalline Diamond Films Produced by MWPECVD. J. Nanopart. Res. 2013, 15, 1549. 
Table of Contents/Graphical Abstract

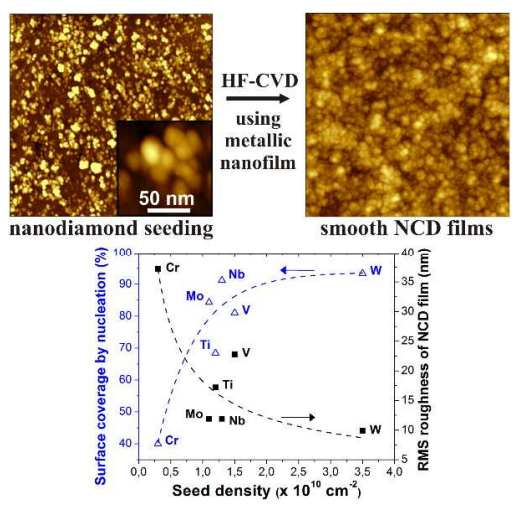

20

21

22

23

24

25

26

27

28

29

30

31

32

33

34

35

36

37

38

39

40

41

42

43

44

45

46

47

48

49

50

51

52

53

54

55

56

57

58

59

60 


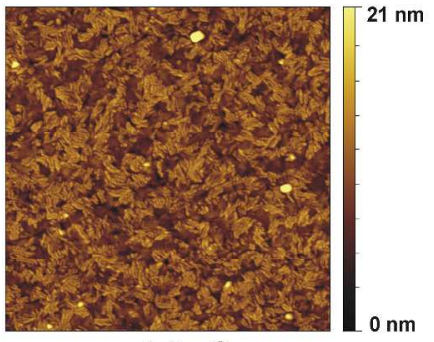

(a) $\mathrm{Cr}$

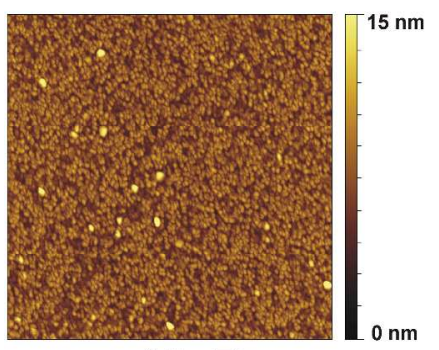

(d) $\mathrm{Ti}$

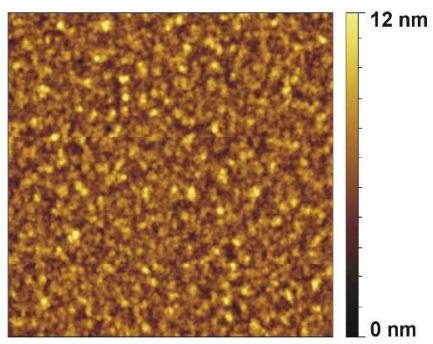

(b) Mo

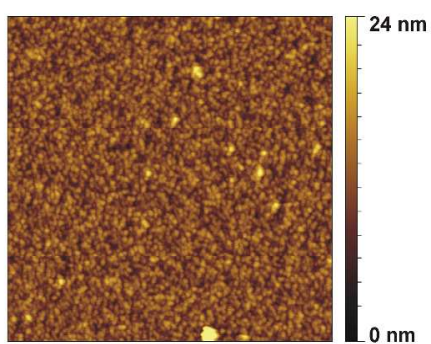

(e) $V$

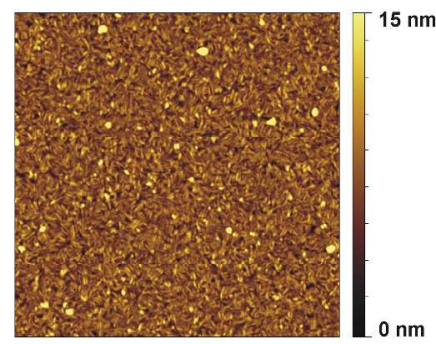

(c) $\mathrm{Nb}$

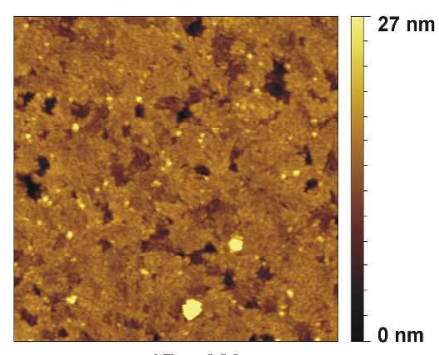

(f) $W$

Figure 1. AFM topographic images $\left(2 \times 2 \mu \mathrm{m}^{2}\right)$ of the six different as-sputtered metallic surfaces on Si-wafer substrates. 


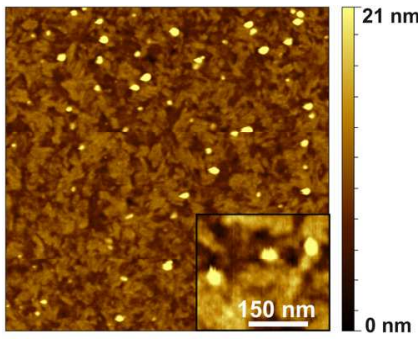

(a) $\mathrm{Cr}$

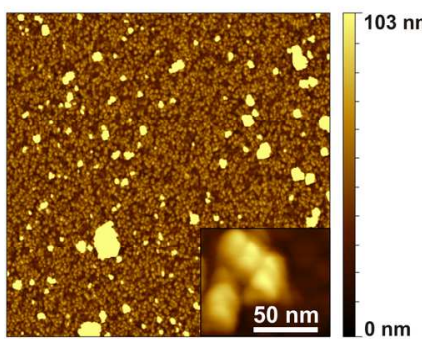

(d) $\mathrm{Ti}$

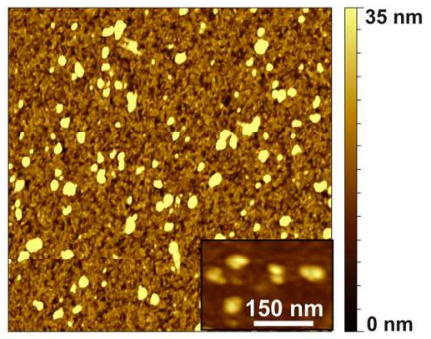

(b) Mo

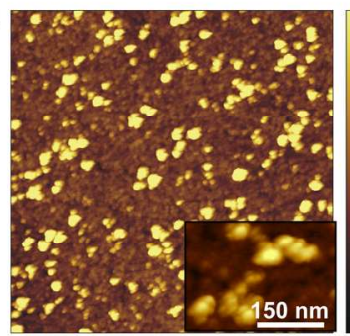

(e) $\mathrm{V}$

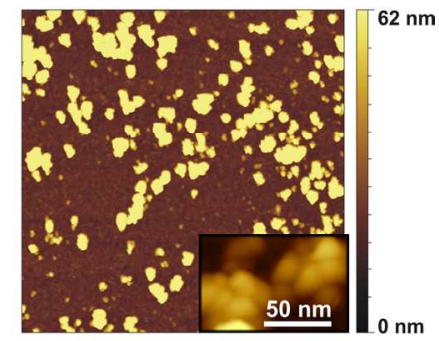

(c) $\mathrm{Nb}$

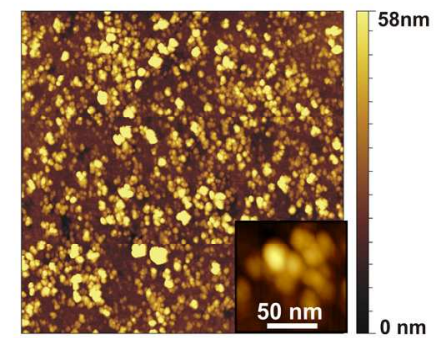

(f) $W$

Figure 2. (a-f) AFM topographic images $\left(2 \times 2 \mu \mathrm{m}^{2}\right)$ of the six different metallic surfaces after the ultrasonic seeding with ND particles and $(\mathrm{g})$ typical surface line profiles measured by AFM on these seeded metallic surfaces.

$173 \times 168 \mathrm{~mm}(300 \times 300$ DPI $)$ 


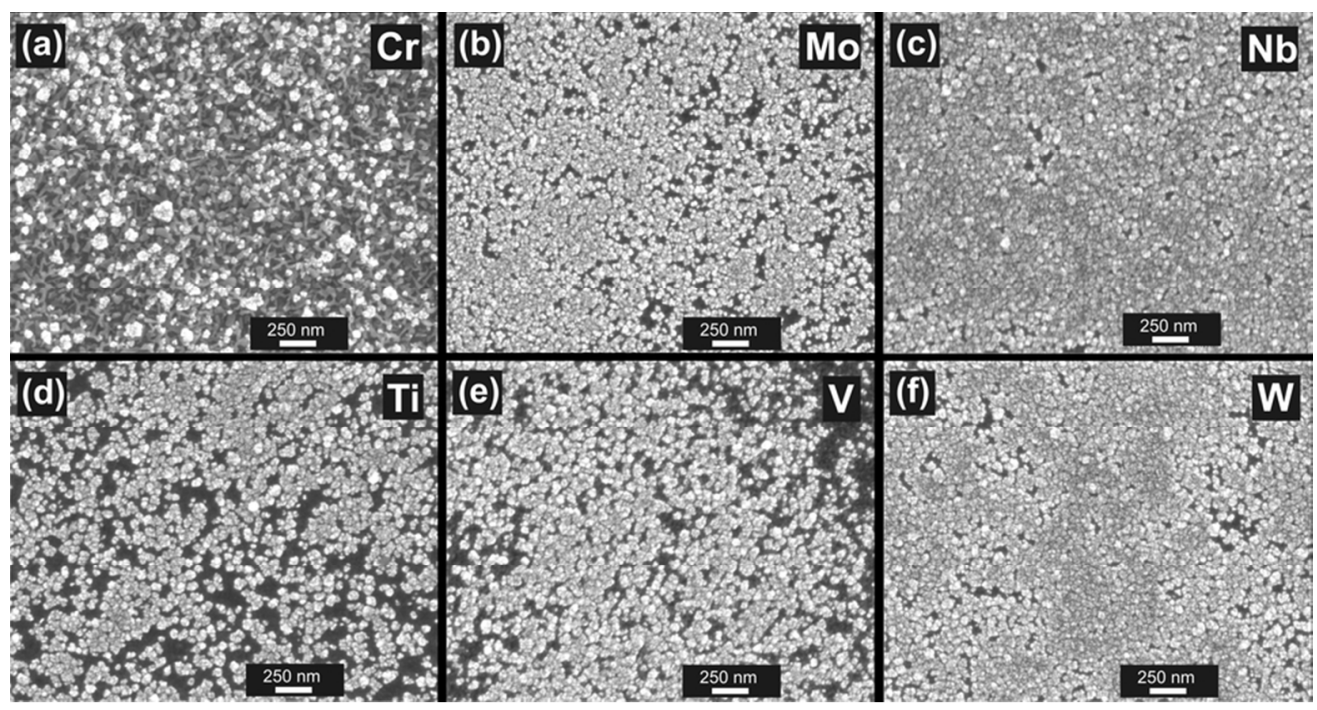

Figure 3. Top-view SEM images taken from the six different metallic surfaces after 2 min of diamond deposition at a substrate temperature of about $650{ }^{\circ} \mathrm{C}$ and using a gas mixture of $2.5 \%$ methane-tohydrogen. Ultrasonic seeding with ND particles was performed prior to the HF-CVD growth process. $81 \times 43 \mathrm{~mm}(300 \times 300$ DPI $)$ 


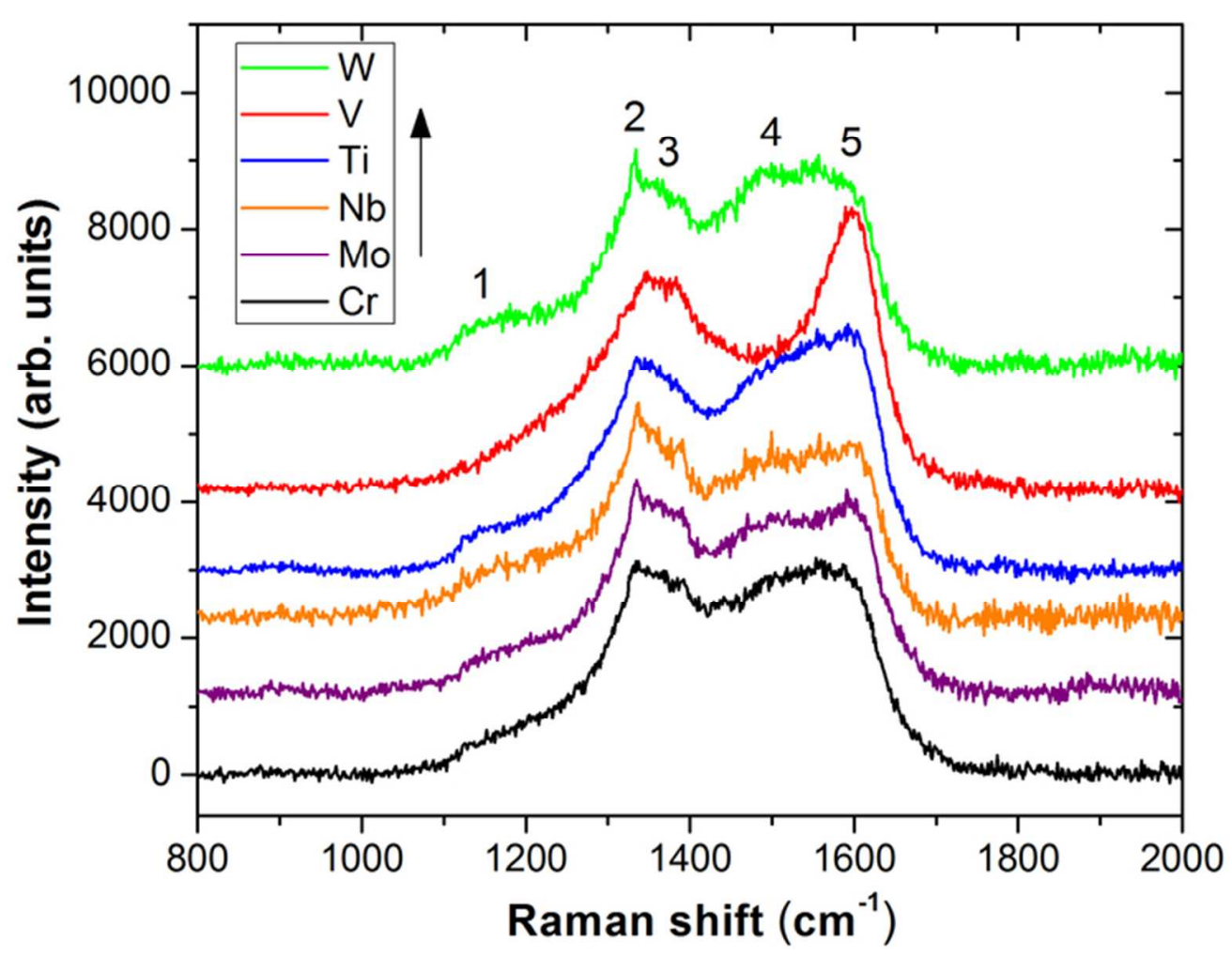

Figure 4. Visible $(514.8 \mathrm{~nm})$ micro-Raman spectra recorded on the six different metallic surfaces after 2 min of diamond nucleation by HF-CVD at a substrate temperature of about $6500^{\circ} \mathrm{C}$ and using a gas mixture of $2.5 \%$ methane-to-hydrogen. The Raman signals labeled 1-5 correspond to signals from trans-polyacetylene (1 and 4), diamond (2), and the D-band (3) and G-band (5) of graphite, respectively. $62 \times 47 \mathrm{~mm}(300 \times 300 \mathrm{DPI})$ 

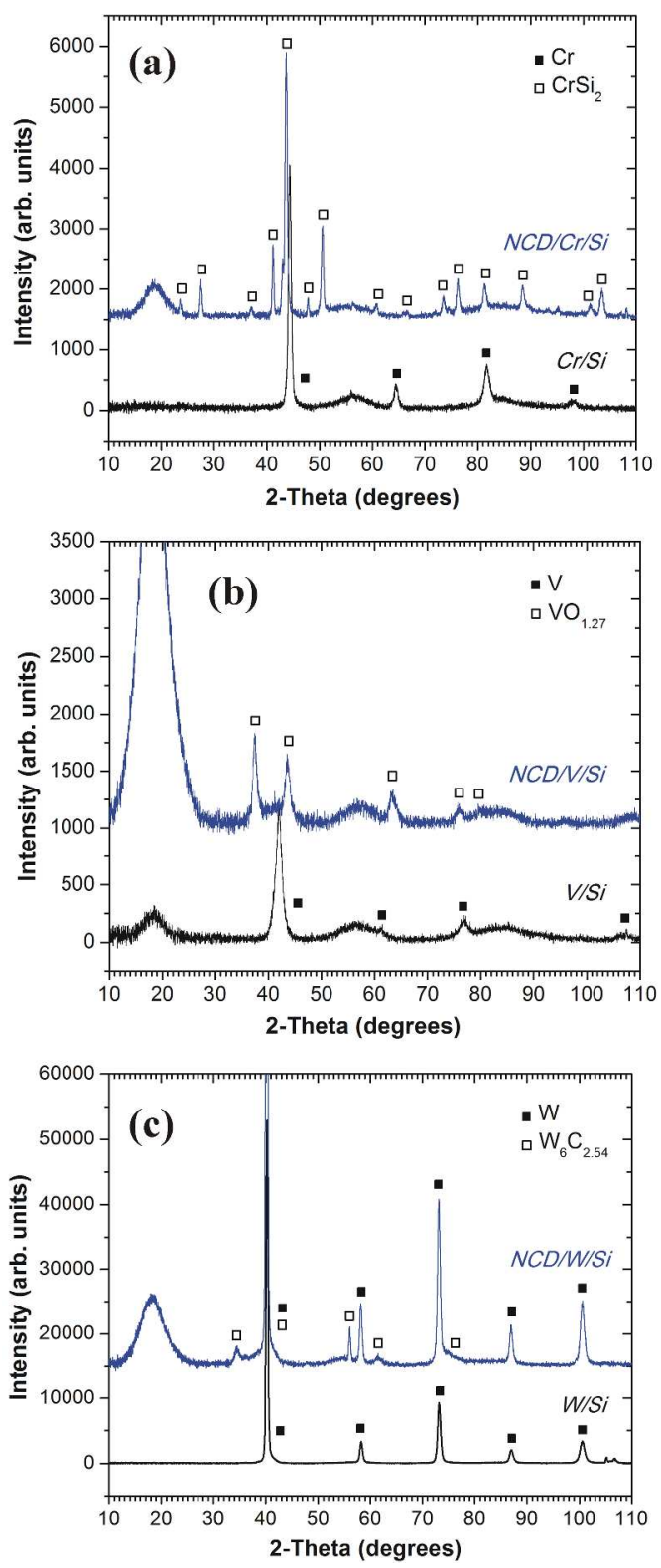

Figure 5. Grazing incidence XRD patterns recorded on the surfaces of the (a) $\mathrm{Cr}$, (b) $V$ and (c) W nanolayers before (lower scans) and after (upper scans) 2 min of diamond nucleation at a substrate temperature of about $650{ }^{\circ} \mathrm{C}$ and using a gas mixture of $2.5 \%$ methane-to-hydrogen. 


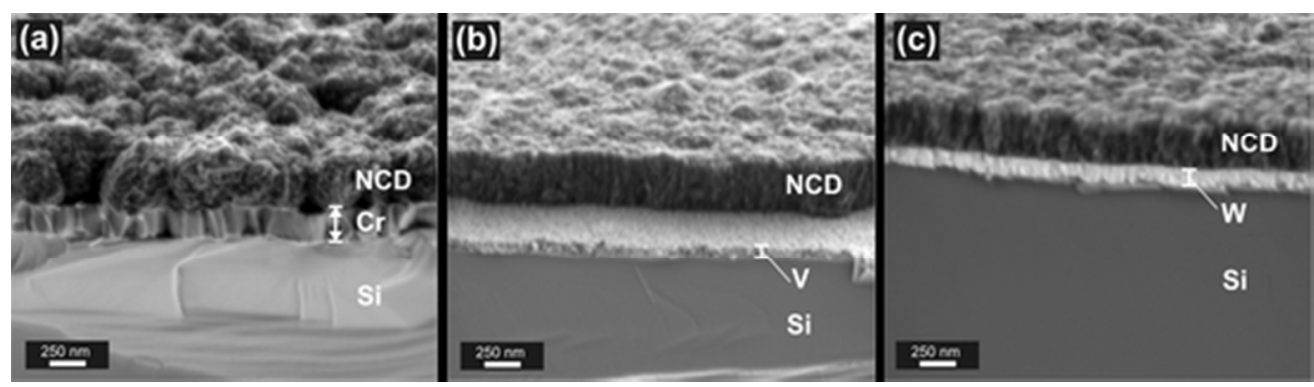

Figure 6. Cross-section SEM images of the NCD films (thickness 300-350 nm) grown on the seeded (a) Cr, (b) V and (c) W nanolayers. NCD film growth was done by HF-CVD during $20 \mathrm{~min}$ at a substrate temperature of about $650{ }^{\circ} \mathrm{C}$ and using a gas mixture of $2.5 \%$ methane-to-hydrogen. Cleavage of the samples was done by using a diamond scribe.

$46 \times 13 \mathrm{~mm}(300 \times 300 \mathrm{DPI})$ 


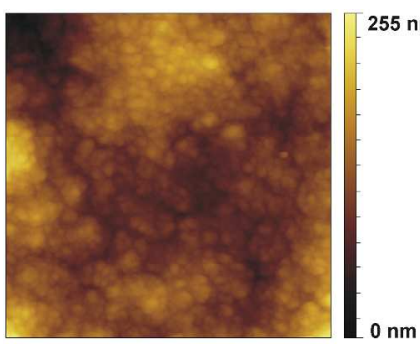

(a) $\mathrm{Cr}$

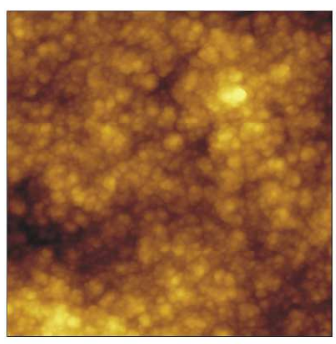

(d) $\mathrm{Ti}$

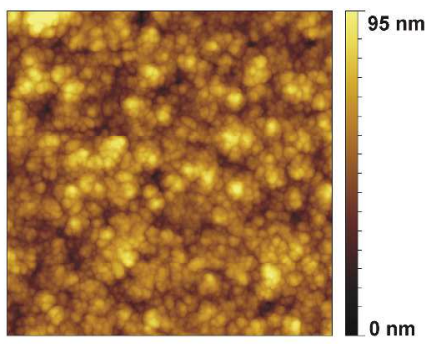

(b) Mo

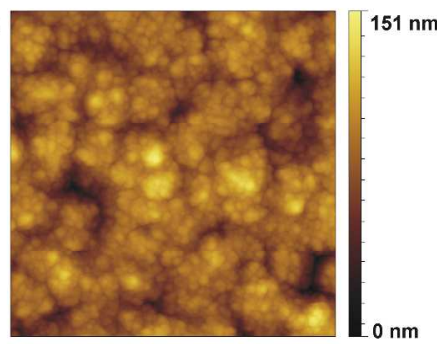

(e) $V$

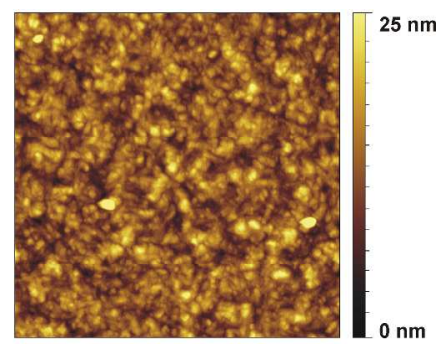

(c) $\mathrm{Nb}$

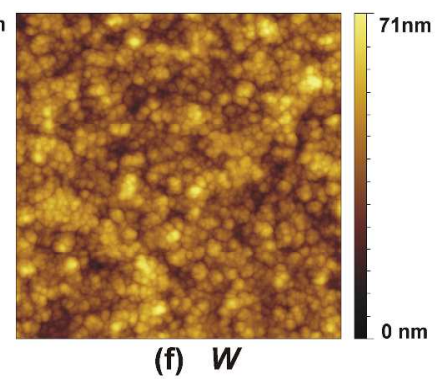

Figure 7. AFM topographic images $\left(2 \times 2 \mu \mathrm{m}^{2}\right)$ of the NCD films (thickness $300-350 \mathrm{~nm}$ ) grown on the six different seeded metallic nanolayers. NCD film growth was done by HF-CVD during 20 min at a substrate temperature of about $650{ }^{\circ} \mathrm{C}$ and using a gas mixture of $2.5 \%$ methane-to-hydrogen. 


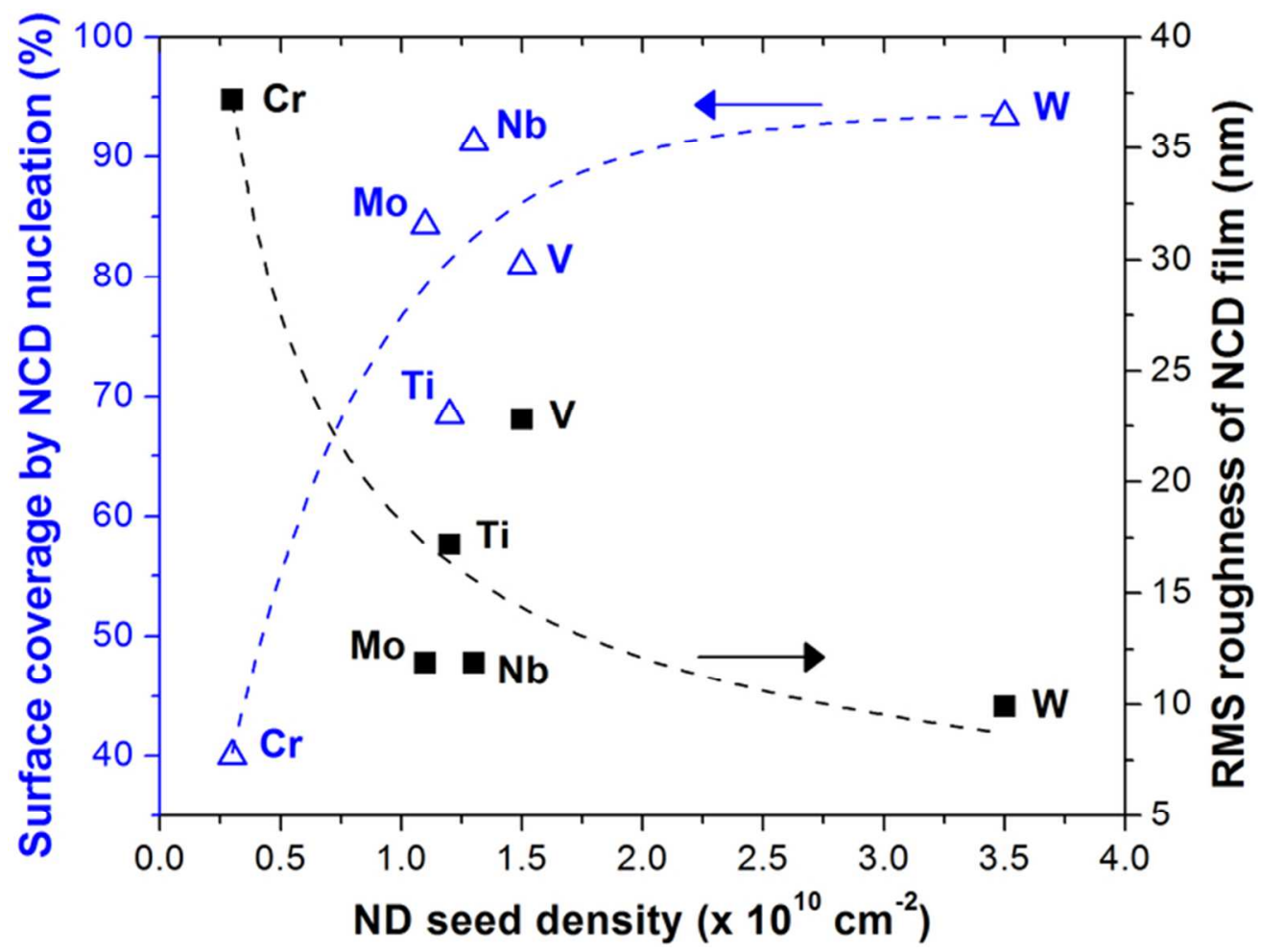

Figure 8. Surface coverage by diamond nucleation (open symbols) and RMS surface roughness of the NCD films (closed symbols) after 2 and 20 min of HF-CVD, respectively, as a function of the number density of ND seed particles on the six different metallic seed nanolayers. The dashed line fits through both data sets are guides to the eye. $61 \times 46 \mathrm{~mm}(300 \times 300 \mathrm{DPI})$ 


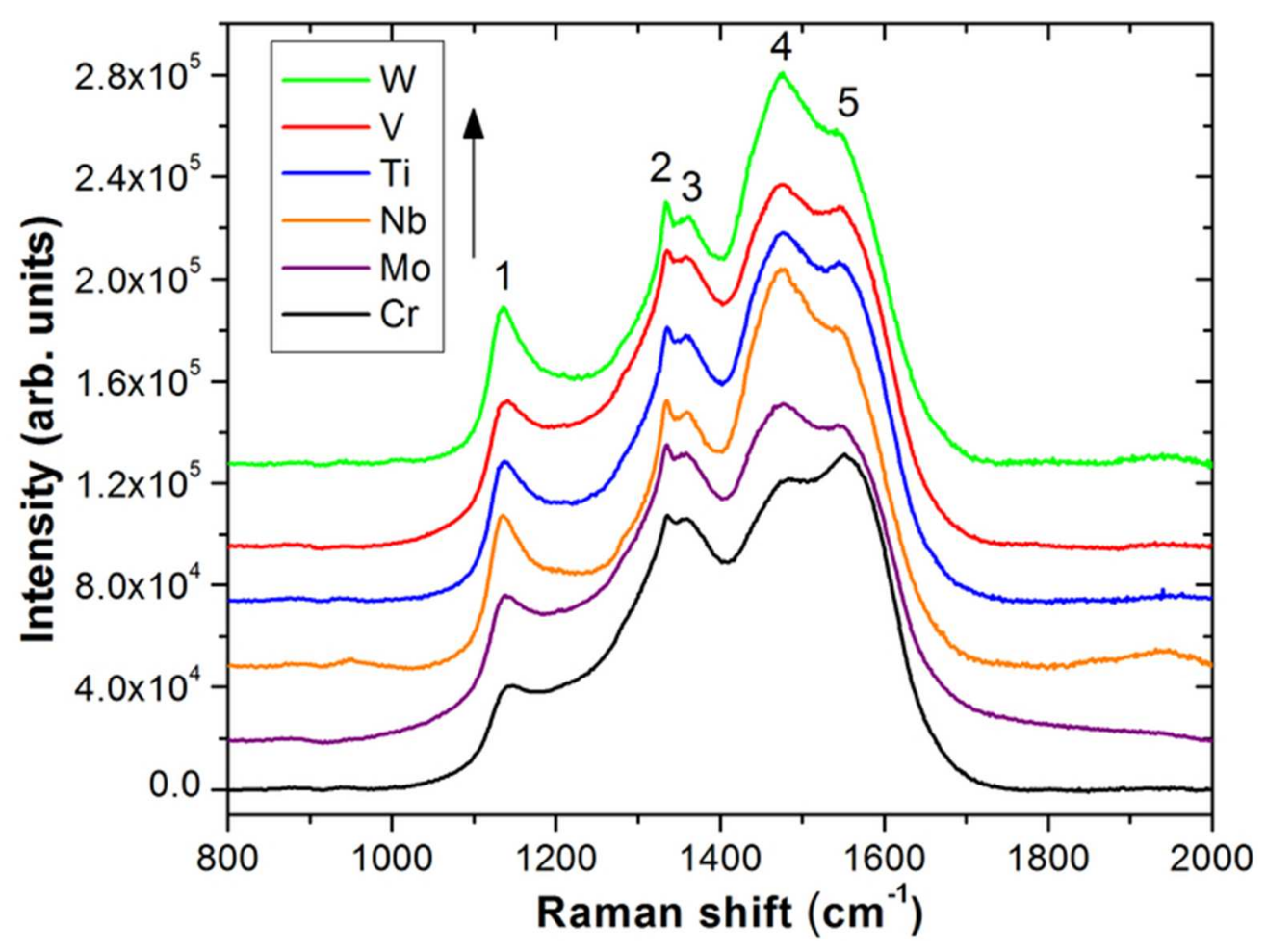

Figure 9. Visible (514.8 nm) micro-Raman spectra of the NCD films (thickness 300-350 nm) grown on the six different seeded metallic nanolayers. NCD film growth was done by HF-CVD during 20 min at a substrate temperature of about $650^{\circ} \mathrm{C}$ and using a gas mixture of $2.5 \%$ methane-to-hydrogen. The Raman signals labeled 1-5 correspond to signals from trans-polyacetylene (1 and 4), diamond (2), and the D-band (3) and G-band (5) of graphite, respectively. $60 \times 44 \mathrm{~mm}(300 \times 300 \mathrm{DPI})$ 